\title{
Interferons and their potential in the treatment of ocular inflammation
}

This article was published in the following Dove Press journal:

Clinical Ophthalmology

15 October 2009

Number of times this article has been viewed

\author{
Friederike Mackensen' \\ Regina Max $^{2}$ \\ Matthias D Becker ${ }^{3}$ \\ 'Department of Ophthalmology, \\ ${ }^{2}$ Department of Internal Medicine, \\ Interdisciplinary Uveitis Center, \\ University of Heidelberg, Germany; \\ ${ }^{3}$ Department of Ophthalmology, \\ Triemli Hospital Zürich, Switzerland
}

Correspondence: Friederike Mackensen Interdisciplinary Uveitis Center,

Dept. of Ophthalmology, University of Heidelberg, Im Neuenheimer Feld 400, D-69120 Heidelberg, Germany

Tel +49-622I-566999

$\mathrm{Fax}+49-622$ I-5633549

Email friederike.mackensen@ uveitiszentrum.de

\begin{abstract}
Since their discovery in the 1950s interferons have been the scope of investigation in many diseases as therapeutic as well as pathogenetic factors. We know they have immune stimulatory and immune regulatory effects. This apparently counter-intuitive mechanism can be summarized as immunomodulatory action and seems to be very effective in a number of ocular inflammatory diseases. We review the current knowledge of interferons in immunity and autoimmunity and show their use in clinical ophthalmologic practice.
\end{abstract}

Keywords: interferon, uveitis, treatment, inflammation

\section{What are interferons?}

Interferons (IFNs) were discovered in $1957^{1}$ as natural antiviral substances produced during viral infection and were characterized for their ability to 'interfere' with viral replication, reduce cell proliferation, and alter immunity. They have received attention because of their diverse effects, influencing both innate and adaptive immune responses; ${ }^{2}$ thus they are involved as well in defense against viral infections, tumor growth, and tolerance induction as well suspected inducers of autoimmune disease, such as sarcoidosis. ${ }^{3,4}$ At the same time they have been used successfully as treatment for autoimmune diseases such as multiple sclerosis. ${ }^{5}$ Thus in autoimmunity IFNs appear as double agents, involved in both supportive and suppressive action.

The different IFNs have been classified into type I, with the large group of IFN- $\alpha$ isotypes and IFN- $\beta$ as the most immunologically relevant, and type II, with the single member IFN- $\gamma$, based on their amino acid composition and biologic properties. Type I IFNs share a common receptor, the IFN- $\alpha / \beta$ receptor, IFNAR, whereas IFN- $\gamma$ as the only representative of type II IFNs binds to a different receptor, IFNGR.

There is a single IFN- $\beta$, while there are at least 13 different IFN- $\alpha$ isotypes. Evidence suggests that they have distinct functions. Their expression seems to depend on the stimulating agent and the cell type. ${ }^{6}$

In addressing the role of IFN- $\alpha / \beta$ in autoimmunity, it is important to recognize that in addition to direct action their effect may be mediated by synergistic or antagonistic interactions with other cytokines. As the clinical experience is limited mainly to type I IFNs, for sake of clarity and space restrictions we concentrate on these.

Virtually any cell can produce type I IFNs, but antigen presenting cells, especially plasmacytoid dendritic cells, are the main producers of type I IFNs, already at early stages of the immune response. Thus, type I IFNs, especially IFN- $\alpha$, may be the pivotal cytokines linking the innate with the adaptive immune system. Low levels of type I 
IFNs seem to be prerequisites for the upregulation of type I IFNs as a reaction to viral infection and subsequent induction of IFN- $\gamma$ production. This finally leads to the induction and maintenance of T-helper type 1 cells, CD8+ cytotoxic $\mathrm{T}$ cells, and natural killer cells that fight the viral intrusion. In contrast, type I IFNs have also been shown to exert an antiproliferative and proapoptotic effect on T cells. Another IFN effect is the development of tolerance-promoting regulatory $\mathrm{T}$ cells. Equally there has been a positive as well as an inhibitory effect described on B-cell development and survival. ${ }^{6,7}$

IFNs also have been shown to be involved in the pathogenesis of several autoimmune diseases as systemic lupus or type I diabetes. ${ }^{8,9}$ Systemic lupus is a highly heterogeneous, multiorgan disorder primarily afflicting women and is characterized by the production of diverse autoantibodies, predominantly against nucleosomal and spliceosomal antigens. Type I IFNs, central to both innate and adaptive immunity, have received particular attention for their role in the development of autoimmune responses, and a preponderance of evidence supports their disease-promoting activity in lupus (reviewed in). ${ }^{8,10}$ In humans with active disease, levels of IFN- $\alpha$ are increased in serum and affected tissues.

\section{Supposed mechanisms of action}

IFNs are thought to have immunomodulatory effects rather than immunosuppressive mode of action. This is supported by insights from animal models of uveitis (see below), but also from studies in humans that were treated with IFNs.

\section{IFN in animal models}

Experimental autoimmune encephalomyelitis (EAE) is a well-established rodent model of CNS-specific inflammatory disease and is known to be the best animal model for studying the etiology and pathogenesis of encephalomyelitis disseminata (ED). It is mediated by $\mathrm{T}$ cells and results in progressive demyelination and paralysis.

There are several subtypes of $\mathrm{T}$ cells in the immune system. They are distinguished by their surface receptors and cytokine repertoire and their differentiation is influenced by the cytokines in their environment. For quite some time the (dis)balance of TH1 (autoagressive) and Th2 (downregulating) CD4+ T cells was thought to induce autoimmunity. Newer research showed the existence of several more $\mathrm{T}$ cell subtypes, as the CD25+, FOXP3+ T "regulatory" $\mathrm{T}$ cells, or so-called Th17, IL-17 producing, possibly autoimmunity supporting cells. ${ }^{11}$
As in ED, EAE is characterized by a breakdown of the blood-brain barrier. The inflammatory response is characterized by $\mathrm{T}$ cell infiltrates located around vessels of the CNS white matter, by activation of local microglia and astrocytes, and in the most severe cases it may be eventually followed by demyelination. Anterior uveitis (AU) has been found to coincide with EAE in rabbits, monkeys, in the Lewis rat, ${ }^{12,13}$ and in mice. ${ }^{14,15}$ The encephalitogenic $T$ cells are specific for the antigen myelin basic protein (MBP), which is a component of the myelinated sheath surrounding nerve bundles. These myelinated nerve bundles are abundant in the spinal cord and in the iris; thus this "autoantigen" is located at sites of inflammation. In the rodent models of EAE, AU generally persists after the paralysis has subsided. EAE and AU can be induced actively by immunizing with MBP in the presence of adjuvant, or passively by using adoptive transfer of MBP-specific T cells that have been generated against the whole antigen or encephalogenic peptides. Mice deficient in IFN- $\beta$ showed augmented and chronic EAE. ${ }^{16}$ Histopathological investigations of CNS in the effector phase revealed an extensive microglia activation and TNF- $\alpha$ production in IFN- $\beta$ KO mice; this was virtually absent in wildtype littermates. This coincided with an increase in effector functions of T cells in IFN- $\beta$ KO mice. The authors suggested that that the lack of IFN- $\beta$ leads to persistent activation of residual antigen presenting cells, which results in prolonged inflammation and extensive demyelination. Another more recent study used EAE as a model to investigate the role of the TRIF-dependent IFN induction pathway of the innate immune system in the regulation of autoimmune inflammation, showing that Th-17 mediated autoimmune inflammation was negatively regulated via IFN-induced IL-27 production in macrophages. ${ }^{17}$

Another mouse model of intraocular inflammation is experimental autoimmune uveitis (EAU), which is induced by interphotoreceptor retinoid-binding protein (IRBP) in rats or mice. EAU can be mitigated or prevented by IFN- $\alpha 2 \mathrm{a}$ or $-\beta$ treatment, in the animal model even an oral application was shown to be effective. ${ }^{18-21}$

\section{IFN in human disease}

Generally type I IFNs have been shown to have multiple immunostimulatory as well as immunosuppressive effects. $^{6,22}$ On the one hand, a shift towards Th1 T cell response and related cytokines has been shown, an increase in MHC class I expression and cellular adhesion molecules, an increase in cytotoxicity of $\mathrm{T}$ cells, and especially 
increase in numbers as well as in activity of NK cells. ${ }^{23}$ This is helpful to eliminate foreign antigen and would explain the anti-viral and anti-tumor effect, but would at the same time indicate an immune-stimulatory capacity that is promoting autoimmunity rather than treating it. IFN is used in treatment of melanoma, and especially in responders autoimmune disease has been described. ${ }^{24}$ The development of autoimmunity was higher in the extended treatment group. IFNs are also involved in the development of autoimmune diseases as diabetes type I. $^{9}$ Thus, the immunoregulatory effects of IFNs are harder to grasp. Especially in Behçet's disease (BD) investigations have been undertaken: Treusch and colleagues have shown that numbers of g-d T cells are normalized ${ }^{25}$ and soluble TNF receptor increases. ${ }^{26}$ These apparently incompatible stimulatory versus regulatory effects (see Figure 1) were reconciled by more recent results from human studies showing an upregulation of $\mathrm{T}$ regulatory cells in patients with BD treated with IFN. ${ }^{27}$ Wang and colleagues showed that IFN- $\alpha 2 b$ upregulates STAT5 and downregulates STAT3, in conjunction with upregulation of Treg and inhibition of IL-17-expressing lymphocytes in melanoma tissues. ${ }^{28}$ Similarly, it has been shown that IFN- $\beta 1$ a inhibits the secretion of Th17-polarizing cytokines in human dendritic cells via TLR7 up-regulation..$^{29}$ The discovery of the Th17 cell lineage marked a new era in the studies of the autoimmune response, as it resolved many controversial findings not compatible with the Th1 paradigm of autoimmune response. ${ }^{30}$ In summary the influence of type I
IFNs on the immune system is still not fully elucidated, but seems to be a very complex web of dosage, timing, and type of cell involved.

A number of clinical trials and case series have been published on systemic treatment with type I IFNs in uveitis. Table 1 lists these in detail. The mode of administration generally is subcutaneous. Intravitreal application has been tried in only 2 patients with advanced neovascular age-related macular degeneration with little response and was not pursued any further due to a reversible reduction in the light response on electroretinography after 1 month. ${ }^{31}$

\section{Behçet's disease (BD)}

$\mathrm{BD}$ is a multisystem disorder that can affect basically all organs. It is common in countries along the old silk route from Turkey and Japan. Uveitis in a patient with BD is accompanied by severe inflammation with occlusive vasculitis that can lead to visual impairment. Therefore, many drugs have been investigated for their potential in preventing ocular recurrences in patients with $\mathrm{BD}$, including azathioprine,,$^{32}$ cyclosporine $\mathrm{A},{ }^{33}$ and infliximab. ${ }^{34}$

As a viral pathogenesis is thought to play a role in the pathogenesis of BD, IFN- $\alpha$ was introduced in 1986 for its antiviral activity, with encouraging results. ${ }^{35}$ In 1994 Feron et $\mathrm{a}^{36}$ used IFN- $\alpha$ for the first time in patients with ocular BD. Kotter et $\mathrm{al}^{37}$ have published the widest experience in treating patients with BD with IFN- $\alpha$. They published an open, noncomparative prospective study including 50 subjects. In this study, the drug was administered initially at a dose

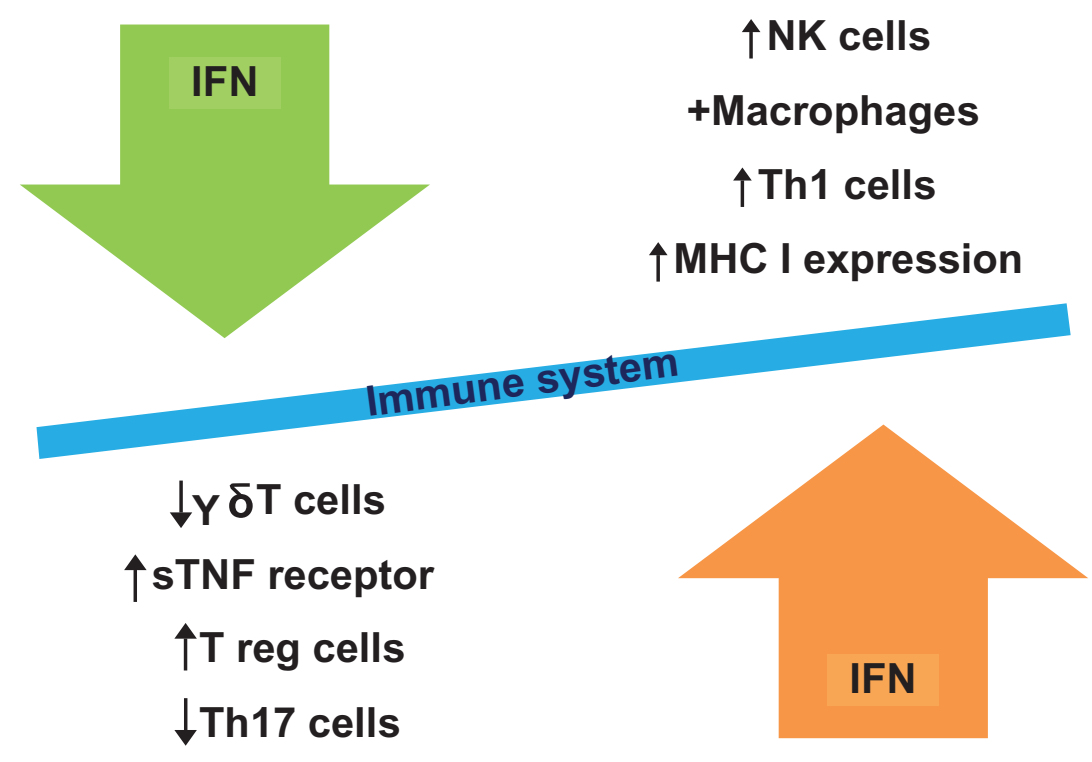

Figure I Interferons: immunostimulatory vs immunoregulatory effects. 
Table I Systemic interferon treatment in ocular inflammatory disease

\begin{tabular}{|c|c|c|c|c|c|c|c|}
\hline Author,Year & Type of study & $\mathbf{n}$ & $\begin{array}{l}\text { Systemic } \\
\text { disease }(n)\end{array}$ & Uveitis (n) & Dose (mio IU) & Interval & $\begin{array}{l}\text { Improvement } \\
\text { (of uveitis) \% }\end{array}$ \\
\hline \multicolumn{8}{|l|}{ Interferon- $\alpha$} \\
\hline Deuter $2009^{64}$ & Retr. CS & 24 & None & 24 & $3-6$ & Daily & $62.5-87.5^{a}$ \\
\hline Krause $2008^{43}$ & Retr. CS & 45 & $\mathrm{BD}$ & 45 & $3-9$ & 3/week & $73-92^{b}$ \\
\hline Gueudry $2008^{47}$ & Retr. CS & 32 & $\mathrm{BD}$ & 32 & 3 & 3/week & $82.1^{c}$ \\
\hline Bodaghi $2007^{46}$ & Retr. CS & 45 & $\begin{array}{l}\mathrm{BD}(23) / \\
\text { other }(22)\end{array}$ & 45 & 3 & 3/week & $\begin{array}{l}82.6 \\
59\end{array}$ \\
\hline $\begin{array}{l}\text { Guillaume-Czitrom } \\
2007^{48}\end{array}$ & Retr. CS & 7 & Pediatric BD & 7 & $1.5-3$ & 3/week & 71.4 \\
\hline Plskova $2007^{65}$ & Pros. CS & 12 & BD (2)/none (I0) & 12 & 6 & Daily & 83 "clinical response" \\
\hline Tugal-Tutkun $2006^{42}$ & Retr. CS & 44 & $\mathrm{BD}$ & 44 & $3-6$ & Daily & $36.4-9 I^{d}$ \\
\hline Kotter $2004^{44}$ & Retr. Meta-analysis & 338 & $\mathrm{BD}$ & 182 & variable & variable & 94 \\
\hline Kotter $2004^{37}$ & Pros. open label & 50 & $\mathrm{BD}$ & 50 & $6-3$ & $\begin{array}{l}\text { Daily to } \\
\text { 3/week }\end{array}$ & 92 \\
\hline Alpsoy $2002^{38}$ & Pros., controlled & 50 & $\mathrm{BD}$ & 9 & 6 or placebo & 3/week & 83 versus 33 \\
\hline \multicolumn{8}{|l|}{ Interferon- $\beta$} \\
\hline Becker $2005^{56}$ & Retr. CS & 13 & Multiple sclerosis & 13 & $\begin{array}{l}22 / 44 \mu \mathrm{g} \mathrm{sc}(10) \\
30 \mathrm{mg} \mathrm{im} \mathrm{(3)}\end{array}$ & $\begin{array}{l}\text { 3/week or } \\
\text { I weekly }\end{array}$ & 71 \\
\hline
\end{tabular}

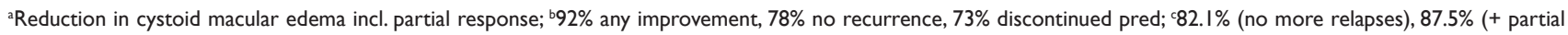
response); ${ }^{3} 36.4 \%$ (no more relapses), $91 \%$ (+ partial response)

Abbreviations: mio IU, million international units; sc, subcutaneously; im, intramuscularly; BD, Behçet's disease; CS, case series.

of 6 million units daily, with dose and frequency adjusted depending on the clinical response. A response rate of $92 \%$ was reported, with significant improvements in both visual acuity and posterior uveitis score. More than one third of patients were off treatment and disease-free at an average of 2.5 years. The IFN treatment was also beneficial for extraocular manifestations of $\mathrm{BD}$, although less so for oral ulcerations.

Alpsoy and colleagues ${ }^{38}$ performed a randomized, placebo-controlled, double-blind trial showing IFN- $\alpha 2$ a to be superior to placebo in oral and genital ulcer reduction as well as in ocular flare reduction. The study included 50 patients, of whom nine had ocular involvement. Other groups have published case series supporting therapeutic effects of IFN- $\alpha$ in this subtype of uveitis. ${ }^{39-43}$

There have been 2 meta-analysis of the literature performed. ${ }^{44,45}$ The first analysis included 32 original reports and 4 selected abstracts. Systemic IFN- $\alpha$ was administered to 338 patients, including 182 with acute ocular disease. Eighty-six percent of the patients with mucocutaneous symptoms, $96 \%$ with arthritis, and $94 \%$ with uveitis exhibited a partial or complete response. Higher IFN doses were more effective than low-dose regimens. Long-term remissions seem to be associated with higher doses, but not longer duration of treatment. IFN- $\alpha 2 \mathrm{a}$ apparently was superior to IFN- $\alpha 2 b$.
The second included 22 studies with 144 participants (some participants were shared between studies). Fourteen studies (70 participants) reviewed treatment with IFN- $\alpha 2 \mathrm{a}$ and 8 studies ( 74 participants) reviewed treatment with IFN- $\alpha 2 b$. Seventy-four percent of patients with mucocutaneous manifestations, $95 \%$ of patients with uveitis, and $93 \%$ of patients with arthropathy/arthritis exhibited a partial or complete response. IFN- $\alpha 2$ a regimens were more effective than IFN- $\alpha 2 \mathrm{~b}$ ones on mucocutaneous ( $47 \%$ versus $7 \%$ complete response) and ocular ( $67 \%$ versus $8 \%$ complete response; $P<0.001)$ manifestations.

Bodaghi and colleagues presented a retrospective evaluation of 45 patients treated with IFN- $\alpha 2 a{ }^{46}$ About half of the patients had BD. Especially in these patients, the treatment was effective $(82.6 \%)$, but it was also judged effective in $59 \%$ of the patients with other types of uveitis. Subsequently, it was possible to significantly reduce oral prednisone in both groups. The same group published their results for 32 patients with BD and IFN in $2008^{47}$ and also for pediatric BD. ${ }^{48}$ In contrast to the Koetter group, these authors started IFN treatment together with an iv methylprednisolone pulse and subsequent oral taper, reaching a final mean of $7 \mathrm{mg}$ of oral prednisone/day. Colchicine was allowed as adjunct treatment. Another group recently published their long-term results on 45 patients with $\mathrm{BD}$ and also started with $100 \mathrm{mg}$ of prednisone and subsequent rapid taper down to $10 \mathrm{mg}$ in 
2 weeks. ${ }^{43}$ See also below for controversial opinions about additional immunosuppressive treatment.

Several case series about the effective use of IFN- $\alpha$ inhibitors in $\mathrm{BD}$ have been published (for a review see ${ }^{49}$ ). EULAR recommendations say to introduce either cyclosporine or infliximab as a second line agent in refractory eye involvement; alternatively IFN- $\alpha$ can be used..$^{50}$ So far no direct comparison of IFN- $\alpha$ inhibitors and IFNs or other immunosuppressive agents and IFN have been performed, but a multicentric national trial is currently ongoing comparing IFN versus cyclosporine (INCYTOB, see clinicaltrials.gov).

\section{Encephalomyelitis disseminata (multiple sclerosis)}

Intermediate uveitis is the most frequent form of ED-associated uveitis. Anterior uveitis is rare in patients with $\mathrm{ED}$, but if it occurs is of the granulomatous subtype..$^{51,52} \mathrm{~A}$ sign of intermediate uveitis are snowbanks and snowballs. Especially in intermediate uveitis accompanying ED, snowbanks and continous retinal periphlebitis in combination seem to be typical. ${ }^{53,54}$ In patients with this type of uveitis, secondary changes like the formation of cystoid macular edema (CME) or occlusive vasculitis with vasoproliferations can develop (Figure 1), which may be complicated by retinal detachments or vitreous hemorrhage. ${ }^{55}$ Especially macular edema with subsequent epiretinal membrane formation is a challenge and a threat to visual prognosis.

There is increasing evidence that IFN is very effective in treatment of uveitis associated with ED, especially the accompanying macular edema. We used type 1 IFNs to treat uveitis associated with multiple sclerosis that was refractory to corticosteroid treatment in a retrospective, multicenter observational case series. Thirteen patients ( 8 female, 5 male) with proven multiple sclerosis and associated uveitis in 25 eyes from 5 uveitis centers were treated with IFN- $\beta 1$ a. Visual acuity improved in 17 eyes ( $71 \%), 5$ did not change (21\%), and 2 eyes deteriorated ( $8 \%$ ) because of development of cataract. CME resolved after or during IFN treatment in $82 \%$ of the eyes. Side effects were noted in three patients (elevation of liver enzymes in 1 patient, depression in 1 , and joint pain in 1). At the last visit, 9 patients $(69 \%)$ had discontinued systemic corticosteroids; 3 were taking $10 \mathrm{mg}$ of prednisone or less. Treatment of multiple sclerosis-associated uveitis with IFN appeared to have beneficial effects on visual acuity, intraocular inflammation activity, and the presence of $\mathrm{CME}$ in this study ${ }^{56,57}$ First results of a randomized, controlled, clinical trial have been presented at the Association for
Research in Vision and Ophthalmology (ARVO) meeting, indicating superiority of IFN over methotrexate in patients with intermediate uveitis with or without ED. ${ }^{58}$

\section{Inflammatory macular edema}

Macular edema is a major cause of vision loss in patients with uveitis. ${ }^{59}$ Diverse treatments are in use, which include periocular or intravitreal corticosteroid injections, systemic corticosteroids, acetazolamide, immunosuppressive medications, octreotides and even intravitreal bevacizumab injections. ${ }^{60-63}$ None of these medications has been tested in a randomized, controlled, clinical trial.

Deuter et $\mathrm{al}^{57}$ were the first to show a positive effect of IFN- $\alpha$ on uveitic CME in a prospective case series. The authors treated 8 patients ( 2 male, 6 female) with IFN- $\alpha 2$ a at an initial dosage of 3 or 6 million units daily, depending on body weight. All patients had inactive primary uveitis with CME that had not responded to systemic corticosteroids and acetazolamide previously. In seven patients, a response to IFN- $\alpha 2$ a was seen within 3 days, and CME completely disappeared after 2 to 4 weeks in all 13 eyes in these patients. In the nonresponder, anti-IFN- $\alpha 2 \mathrm{a}$ antibodies were discovered. Recently, the authors published their experiences in the long-term treatment of 24 patients. ${ }^{64}$

\section{Other uveitis subtypes}

Plskova $^{65}$ and colleagues published their experiences with IFN-alpha $2 b$ in severe posterior or panuveitis. Two of their patients were diagnosed with BD, 1 sympathetic ophthalmia, the rest were idiopathic. A positive clinical response was observed in $83 \%$ of their patients. Bodaghi and coauthors published a retrospective evaluation of 45 patients treated with IFN- $\alpha 2 a .{ }^{46}$ About half of the patients had BD, but 22 had other forms of uveitis. In $59 \%$ of these patients, the treatment was judged effective.

\section{Specifics of IFN treatment Types of IFN available for treatment}

Three different IFN- $\beta$ drugs $\left(\right.$ Avonex $^{\circledR}[\beta 1 \mathrm{a}], \operatorname{Rebif}^{\circledR}[\beta 1 \mathrm{a}]$, Betaseron ${ }^{\circledR}[\beta 1 b]$ ) and 2 IFN- $\alpha$ drugs (Intron $A^{\circledR}[$ IFN- $\alpha 2 b]$, Roferon $\left.{ }^{\circledR}[\mathrm{IFN}-\alpha 2 \mathrm{a}]\right)$ are available.

\section{IFN \pm other immunosuppressive treatment?}

Owing to the particular mode of action of IFNs (immunomodulatory rather than immunosuppressive), it is thought that IFNs need an unsuppressed immune system. 
In $2006^{66}$ we wrote in a similar review on IFNs "Therefore, it is recommended to use additional corticosteroids only in low doses. The concurrent use of immunosuppressives should be avoided during IFN treatment." This was proposed especially by Kotter and coworkers previously. ${ }^{67}$ They based this recommendation on their clinical experience, ${ }^{68}$ backed up by the rationale that the activity of $\mathrm{NF \kappa B}$ is reduced by glucocorticoids. NF $\kappa \mathrm{B}$ is a transcription factor that is thought to regulate the sensitivity of cells toward IFN-mediated antiviral activity ${ }^{69}$ and is itself activated by IFN in a signaling pathway that protects cells against apoptosis. ${ }^{70}$ Recently, several authors/ studies put this paradigm to a test: Gueudry et al ${ }^{47}$ treated BD uveitis with initial methylprednisolone pulse and IFN- $\alpha$ and never aimed to taper corticosteroids completely. In a case series of 2 patients with BD and uveitis Harmuryudan et $\mathrm{al}^{71}$ combined IFN and azathioprine with good results. As can be seen in Table 1, different groups have used IFNs in combination with immunosuppressive agents. There is also increasing evidence from the ED literature that adding corticosteroids or other immunosuppressives to IFN reduces formation of neutralizing antibodies and thus improves clinical response. ${ }^{72}$ Especially one pilot study could show this for a combination of IFN- $\beta 1 \mathrm{a}$ and mycophenolate mofetil (Cellcept $\left.{ }^{\circledR}\right),{ }^{73}$ clinical trials addressing this topic are currently undertaken.

Apparently this is a preventive measure and does not work once neutralizing antibodies have been formed. ${ }^{74}$

\section{Management of IFN therapy}

A close collaboration between other specialists and ophthalmologists is helpful to optimally direct IFN treatment. It is necessary to perform an exact medical history before starting IFN therapy focusing on autoimmune diseases (besides uveitis), impaired thyroid or liver function, and previous or current depressive disorders in particular antecedents of suicidal ideation. Patients should be informed of the most frequent adverse reactions associated with IFN therapy to improve compliance.

\section{Secondary effects}

Common side effects of IFN include injection-site reactions, flu-like symptoms (fever, headache, myalgia, arthralgia, sweating, and fatigue), leukopenia, liver enzyme elevations, and alopecia. The flu-like symptoms can be alleviated by concomitant administration of paracetamol and seem to represent a good prognostic marker for a response to IFN treatment, as this may indicate the absence of preexisting anti-IFN autoantibodies. Usually, severity of these symptoms will decrease in the course of therapy. Patients with cardiac disease, such as angina, congestive heart failure, or arrhythmia, should be closely monitored for worsening of their clinical condition during initiation of therapy with IFNs as symptoms of the flu-like syndrome may prove stressful to patients with cardiac conditions.

Depression and suicidal intentions can occur during therapy with IFN independent of preexisting psychiatric disease. ${ }^{75}$ Patients treated with IFNs should be advised to immediately report any symptoms of depression and/or suicidal ideation to their prescribing physician.

IFN- $\alpha$ in combination with ribavirin treatment in hepatitis $\mathrm{C}$ infection has led to development of sarcoidosis in some patients. ${ }^{3}$ If this is due to $\mathrm{HCV}$ itself acting as antigenic trigger for the development of sarcoidosis in susceptible patients, or the action of ribavirin in combination with IFN- $\alpha$, or the latter alone is unknown so far. Of interest, no reports of IFN- $\beta$ leading to sarcoidosis have been published so far, and no patients treated with IFN- $\alpha$ for other diseases such as $\mathrm{BD}$ have been diagnosed with sarcoidosis. Still, this may be due to the lower numbers in these cohorts.

Retinopathy (cottonwool spots and/or hemorrhages) has been reported as an ocular complication of hepatitis $\mathrm{C}$ treatment with IFN, with frequencies varying from 3.8\% to $24 \%$ in studies, but generally with a good outcome. ${ }^{76-79}$ There are also about 6 single case reports of multiple sclerosis-related IFN-associated retinopathy. ${ }^{80-82}$

IFN therapy may induce formation of autoantibodies and other immune-mediated diseases as auto-immune thyroiditis. $^{24}$

\section{Laboratory exams}

Laboratory abnormalities are associated with the use of IFNs. Basic lab tests include complete and differential blood count, platelets, and liver enzymes (especially ALT). Lab tests should be repeated at months 1,3 , and 6 on therapy and periodically thereafter. Dose reduction of IFN therapy should be considered if ALT rises above 5 times the upper normal limit. Patients being treated with IFNs may occasionally develop new or worsening thyroid abnormalities. Thyroid function testing is recommended at baseline and if abnormal, every 6 to 12 months after initiation of therapy. If tests are normal at baseline, routine testing is not needed but should be performed if clinical findings of thyroid dysfunction appear (ref: Summary of Product Characteristics).

\section{Conclusion}

IFNs have been shown highly effective in the treatment of uveitis. Most data exist for IFN- $\alpha 2 \mathrm{a}$ in $\mathrm{BD}$, from 1 placebo 
controlled trial and 2 meta-analyses. IFN- $\alpha$ may be given for ocular BD not responsive to a first-line immunosuppressive, as per EULAR recommendations. ${ }^{50}$ Evidence is emerging for the use of IFN in the treatment of inflammatory macular edema, but final results from a prospective clinical trial are lacking.

\section{Disclosures}

The authors are performing a clinical trial on interferon beta in patients with uveitic macular edema, partially supported by Merck Serono GmbH.

\section{References}

1. Isaacs A, Lindenmann J. Virus interference. I. The interferon. Proc $R$ Soc Lond B Biol Sci. 1957;147(927):258-267.

2. Baccala R, Kono DH, Theofilopoulos AN. Interferons as pathogenic effectors in autoimmunity. Immunol Rev. 2005;204:9-26.

3. Adla M, et al. Hepatic sarcoidosis associated with pegylated interferon alfa therapy for chronic hepatitis C: case report and review of literature. Dig Dis Sci. 2008;53(10):2810-2812.

4. Doycheva D, et al. Interferon-alpha-associated presumed ocular sarcoidosis. Graefes Arch Clin Exp Ophthalmol. 2009;247(5):675-680.

5. Lublin F. History of modern multiple sclerosis therapy. J Neurol. 2005;252 Suppl 3:iii3-iii9.

6. Theofilopoulos AN, et al. Type I interferons (alpha/beta) in immunity and autoimmunity. Annu Rev Immunol. 2005;23:307-336.

7. Baccala R, et al. TLR-dependent and TLR-independent pathways of type I interferon induction in systemic autoimmunity. Nat Med. 2007;13(5):543-551.

8. Banchereau J, Pascual V. Type I interferon in systemic lupus erythematosus and other autoimmune diseases. Immunity. 2006;25(3):383-392.

9. Devendra D, Eisenbarth GS. Interferon alpha - a potential link in the pathogenesis of viral-induced type 1 diabetes and autoimmunity. Clin Immunol. 2004;111(3):225-233.

10. Bennett $\mathrm{L}$, et al. Interferon and granulopoiesis signatures in systemic lupus erythematosus blood. J Exp Med. 2003;197(6):711-723.

11. Steinman L. A brief history of $\mathrm{T}(\mathrm{H}) 17$, the first major revision in the $\mathrm{T}(\mathrm{H}) 1 / \mathrm{T}(\mathrm{H}) 2$ hypothesis of $\mathrm{T}$ cell-mediated tissue damage. Nat Med. 2007;13(2):139-145.

12. Adamus G, et al. Myelin basic protein specific T-Helper cells induce experimental anterior uveitis. J Neurosci Res. 1996;44(6):513-518.

13. Verhagen $\mathrm{C}$, et al. $\mathrm{T}$ cell immunity to myelin basic protein induces anterior uveitis in Lewis rats. J Neuroimmunol. 1994;53(1):65-71.

14. Shao $\mathrm{H}$, et al. Induction of autoimmune encephalomyelitis and uveitis in B6 and $(\mathrm{B} 6 \times \mathrm{SJL})$ mice by peptides derived from myelin/oligodendrocyte glycoprotein. J Neuroimmunol. 2002;132(1-2):117-122.

15. Constantinescu CS, LE. Anterior uveitis in murine relapsing experimental autoimmune encephalomyelitis (EAE), a mousemodel ofmultiple sclerosis (MS). Curr Eye Res. 2000;20(1):71-76.

16. Teige I, et al. IFN-beta gene deletion leads to augmented and chronic demyelinating experimental autoimmune encephalomyelitis. J Immunol. 2003;170(9):4776-484.

17. Guo B, et al. The type I IFN induction pathway constrains Th17mediated autoimmune inflammation in mice. J Clin Invest. 2008;118(5): 1680-1690.

18. Okada AA, et al. Effect of type I interferon on experimental autoimmune uveoretinitis in rats. Ocul Immunol Inflamm. 1998;6(4):215-226.

19. Stubiger N, et al. Interferon alpha 2a in IRPB-derived peptide-induced EAU - part I. Adv Exp Med Biol. 2003;528:537-540.

20. Suzuki J, et al. Oral administration of interferon-beta suppresses experimental autoimmune uveoretinitis. Graefes Arch Clin Exp Ophthalmol. 2002;240(4):314-321.
21. Mizuguchi J, et al. Type I interferons as immunoregulatory molecules; implications for therapy in experimental autoimmune uveoretinitis. Arch Immunol Ther Exp (Warsz). 2002;50(4):243-254.

22. Brassard DL, et al. Interferon-alpha as an immunotherapeutic protein. J Leukoc Biol. 2002;71(4):565-581.

23. Pfeffer LM, et al. Biological properties of recombinant alphainterferons: 40th anniversary of the discovery of interferons. Cancer Res. 1998;58(12):2489-2499.

24. Gogas $\mathrm{H}$, et al. Prognostic significance of autoimmunity during treatment of melanoma with interferon. $N$ Engl J Med. 2006;354(7):709-718.

25. Treusch $\mathrm{M}$, et al. Influence of human recombinant interferon-alpha2a (rhIFN-alpha2a) on altered lymphocyte subpopulations and monocytes in Behcet's disease. Rheumatology (Oxford). 2004;43(10):1275-1282.

26. Kotter I, et al. Cytokines, cytokine antagonists and soluble adhesion molecules in patients with ocular Behcet's disease treated with human recombinant interferon-alpha2a. Results of an open study and review of the literature. Clin Exp Rheumatol. 2005;23(4 Suppl 38):S20-S26.

27. Yang DS, et al. Interferon-alpha in the management of patients with Behcet's disease. Br J Hosp Med (Lond). 2008;69(10):575-579.

28. Wang W, et al. Effects of high-dose IFNalpha2b on regional lymph node metastases of human melanoma: modulation of STAT5, FOXP3, and IL-17. Clin Cancer Res. 2008;14(24):8314-8320.

29. Zhang X, et al. IFN-betala inhibits the secretion of Th17-polarizing cytokines in human dendritic cells via TLR7 up-regulation. J Immunol. 2009;182(6):3928-3936.

30. Iwakura Y. Ishigame H. The IL-23/IL-17 axis in inflammation. J Clin Invest. 2006;116(5):1218-1222.

31. Kertes PJ, et al. Intravitreal interferon alpha- $2 b$ for the treatment of neovascular age-related macular degeneration: a pilot study. Can $J$ Ophthalmol. 1997;32(3):185-188.

32. Yazici $\mathrm{H}$, et al. A controlled trial of azathioprine in Behcet's syndrome. N Engl J Med. 1990;322:281-285.

33. Nussenblatt RB, et al. Effectiveness of cyclosporin therapy for Behcet's disease. Arthritis Rheum. 1985;28(6):671.

34. Tugal-Tutkun I, et al. Efficacy of infliximab in the treatment of uveitis that is resistant to treatment with the combination of azathioprine, cyclosporine, and corticosteroids in Behcet's disease: an open-label trial. Arthritis Rheum. 2005;52(8):2478-2484.

35. Tsambaos D, et al. Behcet's syndrome: treatment with recombinant leukocyte alpha-interferon. Arch Dermatol Res. 1986;278(4): 335-336.

36. Feron EJ, et al. Interferon-à2b for refractory ocular Behcet's disease. Lancet. 1994;343(8910):1428.

37. Kotter I, et al. Differential efficacy of human recombinant interferonalpha2a on ocular and extraocular manifestations of Behcet disease: results of an open 4-center trial. Semin Arthritis Rheum. 2004;33(5):311-319.

38. Alpsoy E, et al. Interferon alfa-2a in the treatment of Behcet disease: a randomized placebo-controlled and double-blind study. Arch Dermatol. 2002;138(4):467-471.

39. Calguneri M, et al. Effects of interferon alpha treatment on the clinical course of refractory Behcet's disease: an open study. Ann Rheum Dis. 2003;62(5):492-493.

40. Wechsler B, et al. Efficacy of interferon alfa-2a in severe and refractory uveitis associated with Behcet's disease. Ocul Immunol Inflamm. 2000;8(4):293-301.

41. Krause L, et al. Interferon alfa-2a in the treatment of ocular Adamantiades-Behcet's disease. Adv Exp Med Biol. 2003;528:511-519.

42. Tugal-Tutkun I, et al. Results of interferon-alfa therapy in patients with Behcet uveitis. Graefes Arch Clin Exp Ophthalmol. 2006;244(12): $1692-1695$.

43. Krause L, et al. Long term visual prognosis of patients with ocular Adamantiades-Behcet's disease treated with interferon-alpha-2a. J Rheumatol. 2008;35(5):896-903.

44. Kotter I, et al. The use of interferon alpha in Behcet disease: review of the literature. Semin Arthritis Rheum. 2004;33(5):320-335.

45. Zouboulis CC, Orfanos CE. Treatment of Adamantiades-Behcet disease with systemic interferon alfa. Arch Dermatol. 1998;134(8):1010-1016. 
46. Bodaghi B, et al. Efficacy of interferon alpha in the treatment of refractory and sight threatening uveitis: a retrospective monocentric study of 45 patients. Br J Ophthalmol. 2007;91(3):335-339.

47. Gueudry J, et al. Long-term efficacy and safety of low-dose interferon alpha2a therapy in severe uveitis associated with Behcet disease. Am J Ophthalmol. 2008;146(6):837-844.

48. Guillaume-Czitrom S, et al. Efficacy and safety of interferon-alpha in the treatment of corticodependent uveitis of paediatric Behcet's disease. Rheumatology (Oxford). 2007;46(10):1570-1573.

49. Sfikakis PP, et al. Anti-TNF therapy in the management of Behcet's disease - review and basis for recommendations. Rheumatology (Oxford). 2007;46(5):736-741.

50. Hatemi G, et al. EULAR recommendations for the management of Behcet disease. Ann Rheum Dis. 2008;67(12):1656-1662.

51. Lim JI, et al. Anterior granulomatous uveitis in patients with multiple sclerosis. Ophthalmology. 1991;98:142-145.

52. Meisler DM, et al. Anterior uveitis and multiple sclerosis. Cleve Clin J Med. 1989;56:535-538.

53. Breger BC, Leopold IH. The incidence of uveitis in multiple sclerosis. Am J Ophthalmol. 1966;62:540-545.

54. Biousse V, et al. Multiple sclerosis associated with uveitis in two large clinic-based series. Neurology. 1999;52(1):179-181.

55. Valentincic N, et al. Vitreous hemorrhage in multiple sclerosisassociated uveitis. Ocul Immunol Inflamm. 2007;15(1):19-25.

56. Becker MD, et al. Interferon as a treatment for uveitis associated with multiple sclerosis. Br J Ophthalmol. 2005;89(10):1254-1257.

57. Deuter CM, et al. Interferon alfa-2a: a new treatment option for long lasting refractory cystoid macular edema in uveitis? A pilot study. Retina. 2006;26(7):786-791.

58. Becker M, et al. First results of a randomized controlled clinical trial comparing interferon beta with methotrexate for the treatment of intermediate uveitis with macular edema. Invest Ophthalmol Vis Sci. 2008;49:E-Abstract 1118.

59. Rothova A, et al. Causes and frequency of blindness in patients with intraocular inflammatory disease. Br J Ophthalmol. 1996;80:332-336.

60. Mackensen F, et al. Intravitreal bevacizumab (avastin) as a treatment for refractory macular edema in patients with uveitis: a pilot study. Retina. 2008;28(1):41-45.

61. Rothova A. Medical treatment of cystoid macular edema. Ocul Immunol Inflamm. 2002;10(4):239-246.

62. Missotten T, et al. Octreotide long-acting repeatable for the treatment of chronic macular edema in uveitis. Am J Ophthalmol. 2007;144(6): 838-843.

63. Schilling $\mathrm{H}$, et al. Long-term effect of acetazolamide treatment of patients with uveitic chronic cystoid macular edema is limited by persisting inflammation. Retina. 2005;25(2):182-188.

64. Deuter CM, et al. Efficacy and tolerability of interferon alpha treatment in patients with chronic cystoid macular oedema due to non-infectious uveitis. Br J Ophthalmol. 2009;93(7):906-913.
65. Plskova $\mathrm{J}$, et al. Interferon-alpha as an effective treatment for noninfectious posterior uveitis and panuveitis. Am J Ophthalmol. 2007;144(1):55-61.

66. Mackensen F, et al. Interferon therapy for ocular disease. Curr Opin Ophthalmol. 2006;17(6):567-573.

67. Kotter I, et al. Human recombinant interferon alfa-2a for the treatment of Behcet's disease with sight threatening posterior or panuveitis. $\mathrm{Br}$ Ophthalmol. 2003;87(4):423-431.

68. Deuter CM, et al. Behcet's disease: ocular effects and treatment. Prog Retin Eye Res. 2008;27(1):111-136.

69. Pfeffer LM, et al. Role of nuclear factor-kappaB in the antiviral action of interferon and interferon-regulated gene expression. J Biol Chem. 2004;279(30):31304-31311.

70. Yang $\mathrm{CH}$, et al. IFNalpha/beta promotes cell survival by activating NF-kappa B. Proc Natl Acad Sci U S A. 2000;97(25):13631-13636.

71. Hamuryudan $\mathrm{V}$, et al. Interferon alfa combined with azathioprine for the uveitis of Behcet's disease: an open study. Isr Med Assoc J. 2002; 4(11 Suppl):928-930.

72. Pozzilli $\mathrm{C}$, et al. Monthly corticosteroids decrease neutralizing antibodies to IFNbeta1 b: a randomized trial in multiple sclerosis. J Neurol. 2002;249(1):50-56.

73. Vermersch P, et al. Combination of IFN beta-1a (Avonex) and mycophenolate mofetil (Cellcept) in multiple sclerosis. Eur J Neurol. 2007;14(1):85-89.

74. Ravnborg M, et al. Treatment with azathioprine and cyclic methylprednisolone has little or no effect on bioactivity in anti-interferon beta antibody-positive patients with multiple sclerosis. Mult Scler. 2009; 15(3):323-328.

75. Panitch $\mathrm{H}$, et al. Benefits of high-dose, high-frequency interferon beta-1a in relapsing-remitting multiple sclerosis are sustained to 16 months: final comparative results of the EVIDENCE trial. J Neurol Sci. 2005;239(1):67-74.

76. Panetta JD, Gilani N. Interferon induced retinopathy and its risk in patients with diabetes and hypertension undergoing treatment for chronic hepatitis C virus infection. Aliment Pharmacol Ther. 2009 June 22. [Epub ahead of print].

77. Willson RA. Visual side effects of pegylated interferon during therapy for chronic hepatitis C infection. J Clin Gastroenterol. 2004;38(8): $717-722$.

78. Cuthbertson FM, et al. Is screening for interferon retinopathy in hepatitis C justified? Br J Ophthalmol. 2004;88(12):1518-1520.

79. d'Alteroche L, et al. Ophthalmologic side effects during alpha-interferon therapy for viral hepatitis. J Hepatol. 2006;44(1):56-61.

80. Ohira M, et al. Retinopathy: an overlooked adverse effect of interferonbeta treatment of multiple sclerosis. Keio J Med. 2009;58(1):54-56.

81. Saito $\mathrm{H}$, et al. Retinopathy in a multiple sclerosis patient undergoing interferon-therapy. Mult Scler: 2007;13(7):939-940.

82. Folden DV, et al. Interferon beta-associated retinopathy in patients treated for multiple sclerosis. Neurology. 2008;70(13 Pt 2):1153-1155.
Clinical Ophthalmology

\section{Publish your work in this journal}

Clinical Ophthalmology is an international, peer-reviewed journal covering all subspecialties within ophthalmology. Key topics include: Optometry; Visual science; Pharmacology and drug therapy in eye diseases; Basic Sciences; Primary and Secondary eye care; Patient Safety and Quality of Care Improvements. This journal is indexed on Submit your manuscript here: http://www.dovepress.com/clinical-ophthalmology-journal

\section{Dovepress}

PubMed Central and CAS, and is the official journal of The Society of Clinical Ophthalmology (SCO). The manuscript management system is completely online and includes a very quick and fair peer-review system, which is all easy to use. Visit http://www.dovepress.com/ testimonials.php to read real quotes from published authors. 